\title{
Effect of high temperature LiPON electrolyte in all solid state batteries
}

\author{
Alfonso Sepúlveda, ${ }^{\star \neq}$ Francesca Criscuolo, ${ }^{\dagger}$ Brecht Put, ${ }^{\dagger}$ Philippe M. Vereecken ${ }^{\dagger}$ \\ $\dagger$ Imec, Kapeldreef 75, 3001 Leuven, Belgium \\ $\S$ Centre for Surface Chemistry and Catalysis, University of Leuven, Kasteelpark Arenberg 23, 3001 Leuven, \\ Belgium
}

*Corresponding Author: alfonso.sepulvedamarquez@imec.be

Thin film solid state $\mathrm{Li}_{4} \mathrm{Ti}_{5} \mathrm{O}_{12}$-based batteries are developed by using amorphous Lithium Phosphorus Oxynitride (LiPON) electrolyte deposited by reactive sputtering at different substrate temperatures $\left(\mathrm{T}_{\text {dep }}\right)$. Such layers maintain their amorphous character even at higher $\mathrm{T}_{\text {dep }}$. The stoichiometry, ionic conductivity, thermal stability and overall effect on full battery stacks were investigated. The ionic conductivity falls down by nearly three orders of magnitude for samples deposited at higher temperatures while no significant compositional variations are found, in contrast with previous reports. This is interpreted as the creation of a highly thermally stable LiPON glass with a closed-packed structure which inhibits Li-ion diffusion. The onset of the glass transition $\left(\mathrm{T}_{\mathrm{g}}\right)$ and the crystallization temperature $\left(\mathrm{T}_{\mathrm{c}}\right)$ of LiPON shifts to higher temperatures as $\mathrm{T}_{\text {dep }}$ increases. Galvanostatic (dis)charge measurements on fully operational thin film batteries show a decrease in capacity and a worsened Crate performance as LiPON $\mathrm{T}_{\mathrm{dep}}$ increases. Despite the lower ionic conduction, the improved thermal stability reported here using LiPON whose properties can be properly tuned could open interesting scenarios in future advances in solid-state battery systems and new possibilities in high temperature applications. 


\section{INTRODUCTION}

The creation of efficient energy sources is nowadays essential in several applications, including implantable medicine, smart devices and wireless systems. Rechargeable lithium ion batteries are one of the most frequent types of cells employed in portable electronics because of their superior specific power and energy. Nowadays, commonly used rechargeable lithium ion batteries use liquid electrolytes which are characterized by several inherent drawbacks, like the need of separators that limits their downscaling and the high risk of leakage that makes these systems prone to fire and explosion. Thus, suitable solid electrolytes are needed to overcome these drawbacks. Good electrolytes must possess high ionic conductivity, good thermal stability and large electronic insulation. Downscaling of the electrolytes offers higher energy densities, flexibility and longer lifetime. The reduction of layer thickness leads to higher output power due to smaller diffusion distances and hence a faster charge/discharge process. The demand for flexible and lighter batteries with large energy densities and power output is continuously increasing. The use of all solid-state batteries could surmount the limitations in downscaling characteristic of the commonly used lithium ion batteries employing liquid electrolytes.

Solid state electrolytes should be characterized by a large ion transference number (contribution of the ions to the total electric current in the electrolyte), which means they must be good ionic conductors, but electronically insulating to avoid leakage currents that contribute to self-discharge. Moreover, also high chemical, mechanical and thermal stability are crucial. Solid electrolyte materials show many benefits with respect to liquid systems, including a wider electrochemical stability window, easy design, low risk of leakage, non-flammability, resistance to vibration and shock. ${ }^{1,2}$ Solid electrolytes can be both crystalline or amorphous. Glassy electrolytes are in general preferable because of their open structure, wide compositional range, absence of grain boundaries, isotropicity, simple fabrication and downscaling. In addition, they have lower ionic resistance than their crystalline counterparts due to their open structure. On the contrary, crystalline electrolytes requires annealing, limiting the possible choices for multi-layer stacks to materials with limited difference in thermal expansion. Also, intermixing 
between different battery components might occur at high temperature, eventually causing electronic conduction. ${ }^{1,3}$ One of the most used candidates for solid-state batteries since its first introduction by Bates et al. in 1992 has been LiPON (Lithium phosphorous oxynitride). ${ }^{4} \mathrm{LiPON}$ is an amorphous material that due to its negligible electronic conductivity (electronic resistivity of $\sim 10^{14} \Omega \cdot \mathrm{cm}$ ) ${ }^{5}$ and high electrochemical stability window of $5.5 \mathrm{~V}^{6,7}$ has attracted attention not only to work as a solid electrolyte in all solid state thin film batteries but also as protective coating ${ }^{8,9}$ and transparent layer for solid state electrochromic devices. ${ }^{10}$ The ionic conductivity of LiPON is rather low $\left(\mu \mathrm{S} \mathrm{cm}^{-1}\right)$ but its ease of processing and downscaling still makes a strong candidate for future solid state thin film battery development..$^{5,11}$

Amorphous LiPON is grown typically by means of reactive RF-sputtering under $\mathrm{N}_{2}$ from a $\mathrm{Li}_{3} \mathrm{PO}_{4}$ target. ${ }^{6}$ There are other means of preparation such as pulse laser deposition (PLD) ${ }^{1}$, e-beam evaporation $^{12}$, ion-beam direct assembly $(\text { IBDA })^{13}$, ion-beam sputtering $(\text { IBS })^{8}$, ion-beam assisted deposition (IBAD),${ }^{14}$ atomic layer deposition (ALD) $)^{11,15,16}$, metal organic chemical vapor deposition $(\mathrm{MOCVD})^{17}$ and from ammonolysis of melted $\mathrm{LiPO}_{3}{ }^{18}{ }^{1}$ It has been stated in several studies that in reactive RF-sputtering, $\mathrm{N}_{2}$ is incorporated into the material structure by the substitution of bridging oxygen by doubly bonded nitrogen with phosphorus (P-N=P) up to $75 \%$ of its nitrogen atoms. ${ }^{19}$ In addition, increasing the triple coordinated sites may increase the ionic conductivity further. ${ }^{20}$ This is considered a decisive factor to enhance stability and ionic conductivity of LiPON compared to that of $\mathrm{Li}_{3} \mathrm{PO}_{4}{ }^{21}$ Another explanation for the increase of ionic conductivity in LiPON is is related to the decrease of the bridging to non-bridging oxygen ratio $(\mathrm{Ob} / \mathrm{Onb}) .{ }^{22}$ Efforts have been made to try to further increase LiPON ionic conductivity by tuning deposition parameters such as sputtering power, ${ }^{23}$ $\mathrm{N}_{2}$ flow, ${ }^{19}$ pressure, ${ }^{24}$ substrate bias, ${ }^{25}$ temperature ${ }^{26}$ and even post annealing treatments ${ }^{20}$ and cosputtering of different targets. ${ }^{2}$ Up to date, the composition of LiPON films vary up to $10 \%$ depending on the preparation conditions. Ionic conductivity values are widely spread over 2 orders of magnitude, from around 0.1 to $10 \mu \mathrm{S} \mathrm{cm}^{-1}$. 
LiPON is a material which has been widely studied on its own. Despite this, very few reports show complete and functional all-solid state thin film cells and the effect that LiPON solid electrolyte might have on the performance of a full battery stack. ${ }^{27}$. In this work, LiPON thin films are created by means of reactive RF-sputtering at different substrate temperatures. Power, pressure and $\mathrm{N}_{2}$ flow are kept constant to achieved optimum ionic conductivity which has been already reported elsewhere. ${ }^{5}$ The properties of LiPON deposited at different temperatures are studied by means of electrochemical impedance spectroscopy (EIS), X-ray diffraction (XRD), spectroscopic ellipsometry, scanning electron microscopy (SEM) and elastic-recoil detection (ERD). Our results on the ionic conductivity as a function of deposition temperature are in contrast with few reports that show LiPON films grown at different substrate temperatures. ${ }^{25,26}$ We report that the ionic conductivity drops by nearly 3 orders of magnitude in a deposition temperature range from room temperature (RT)-to- $285{ }^{\circ} \mathrm{C}$. This ionic conductivity reduction cannot be explained in terms of compositional variations. We relate this phenomenon to the formation of highly thermodynamically stable LiPON glass, as sustained by the increase in crystallization and glass transition temperatures. We demonstrate that all-solid state thin film Li-batteries can be developed using LiPON electrolyte deposited at higher temperatures. We make use of $\mathrm{Li}_{4} \mathrm{Ti}_{5} \mathrm{O}_{12}$ as a cathode material and $\mathrm{Li}$ metal as anode. The performance of the different batteries is studied by cyclic voltammetry (CV), galvanostatic charge-discharge process at different C-rates and cycling stability tests. We show that LiPON electrolyte grown at different temperatures can have an effect in the overall performance of a thin film solid state battery and that by tuning the deposition temperature of the LiPON electrolyte there is a significant enhancement in thermal stability.

\section{EXPERIMENTAL SECTION}

LiPON layers were deposited by RF sputtering (Pfeiffer, Spider) using a 4" $\mathrm{Li}_{3} \mathrm{PO}_{4}$ target (Praxair, 99.9\% purity). The power and the nitrogen flux were set to $2.7 \mathrm{~W} \mathrm{~cm}^{-2}$ and $30 \mathrm{sccm}$, respectively. Previous reports have shown that the highest conductivity value can be achieved by using these conditions. ${ }^{5}$ Before each deposition a 1 hour pre-sputtering followed by a 15 min conditioning step was performed. The chamber base pressure was kept at $\sim 3 \times 10^{-6}$ Torr. During the deposition of the LiPON 
layers, the pressure was kept at $\sim 3 \times 10^{-3}$ Torr. The substrate temperature during deposition was calibrated using thermal indicator strips (Rachetel,Omega) with overall temperature sensitivity of $10^{\circ} \mathrm{C}$. The temperature accuracy at each setpoint $\left(\mathrm{T}_{\text {setpoint }}\right)$ was determined by the chuck temperature measurement $\left(\mathrm{T}_{\text {measured }}\right)$ of at least $5 \mathrm{LiPO}(\mathrm{N})$ depositions. A temperature stabilization time of 30 minutes was found to be sufficient to avoid thermal spikes and reach a steady substrate temperature during film growth. The measured temperature as a function of $\mathrm{T}_{\text {setpoint }}$ is shown in Figure $\mathrm{S} 1$ of the Supporting Information (SI). After deposition, the films where kept under inert atmosphere to avoid any effects due to prolonged exposure $(<30 \mathrm{~min})$ to moisture. The morphology and thickness of the films were determined by scanning electron microscopy (SEM, Nova) and profilometry (Dektak). The deposition rate was $5 \mathrm{~nm} \mathrm{~min}{ }^{-1}$ for all films. The maximum variation between different samples is less than $5 \mathrm{~nm}$ as shown in Figure 2S. The LiPON thickness is varied according to the sensitivity of the different techniques used for its characterization. A base substrate consisting of sputtered $70 \mathrm{~nm} \mathrm{Pt} / 40$ $\mathrm{nm} \mathrm{TiOx} / 30 \mathrm{~nm} \mathrm{SiOx}$ on $\mathrm{Si}$ was used to grow the LiPON thin films. This base substrate has proven to withstand temperature treatments up to $800^{\circ} \mathrm{C}$. X-ray diffraction analysis (XRD) was performed to determine the amorphous state of the grown LiPON thin films at different temperaturesand different substrates (TiN and Pt). An X-pert pro (Panalytical) tool with $\mathrm{Cu}-\mathrm{K} \alpha$ radiation with a standard power of $45 \mathrm{kV} / 40 \mathrm{~mA}(1000 \mathrm{~W})$ was employed in a grazing angle configuration to record in air XRD spectra of the samples. In-situ XRD was performed under helium in a $2 \theta$ window of $15-35^{\circ}$ from RT up to 900 ${ }^{\circ} \mathrm{C}$. The composition of the deposited LiPON layers was determined by elastic recoil detection (ERD), which makes use of a primary ion beam of $\mathrm{Cl}^{4+}$ accelerated to $8 \mathrm{MeV}$ by a $2 \mathrm{MV}$ tandem accelerator. The scatter and the sample tilting angles were set to $39.6^{\circ} \pm 0.5^{\circ}$ and $10^{\circ}$, respectively. To avoid intense scattering coming from the substrate and improve signal to noise ratio, LiPON layers are deposited in a $\mathrm{TiN} / \mathrm{SiO}_{\mathrm{x}}$ substrate. In this setup, the forward recoiled and scattered ions were detected with a timeof-flight energy (ToFE) telescope. ${ }^{28}$

The temperature onset for the glass transition of the LiPON films was obtain using spectroscopic ellipsometry under He (J. A. Woollam, Inc. M2000U) with a wavelength range of 300-1500 nm. The thin film LiPON samples were modeled as a 3 layer system: $550 \mathrm{~nm} \mathrm{LiPON}, 100 \mathrm{~nm} \mathrm{SiO} 2$ and the $\mathrm{Si}$ 
substrate. The known optical properties for $\mathrm{SiO}_{2}$ and $\mathrm{Si}$ were fixed in the model using CompleteEase software. A Cauchy model was used to describe the optical properties for LiPON. The fitted parameters were determined by minimizing the mean square error (MSE).

Ionic conductivity values were extracted by temperature dependent Solid-state Impedance Spectroscopy (SIS) using a home-made micromanipulated cryogenic probe station. Thin film LiPON layers in a Metal-Electrolyte-Metal (MEM) configuration were fabricated for this purpose. A $150 \mathrm{~nm}$ thin film LiPON is deposited on Pt and Au metal dots from 100 to $500 \mu \mathrm{m}$ diameter are deposited through a shadow mask by thermal evaporation (Alcatel). A sinusoidal $5 \mathrm{mV}$ AC signal is applied through a HP4284A precision LCR meter over a frequency range from $20 \mathrm{~Hz}$ to $1 \mathrm{MHz}$ to the bottom contact $(\mathrm{Pt})$ to limit noise. During measurements the samples were kept under vacuum around $10^{-4}$ $10^{-5}$ Torr to avoid effects of moisture in the LiPON films. Active heating and cooling (using liquid $\mathrm{N}_{2}$ ) was carried out over a range from 200 to $350 \mathrm{~K}$ during data acquisition. Current-voltage and polarization measurements were performed using an Agilent 4156C parameter analyzer. MEISP software by Kumho Chemical Laboratories was used to analyze the impedance results. This is based on the complex nonlinear least-squares fitting algorithm LEVM/LEVMW. A part form the fitting parameters, also values representing the accuracy of the fitting are generated by the software. In order to ensure a good fit the $\chi^{2}$ was always brought to values smaller than $10^{-3}$ and the standard deviation of each parameters to less than 5\%. The impedance data was evaluated using a circuit model consisting of a resistance (Rs) in series with two R/CPE branches followed by another CPE in series. Details on the equivalent circuit model analysis has been discussed elsewhere. ${ }^{5}$ Each SIS measurement was performed on two different LiPON samples deposited at each of the different temperatures using the same nitrogen flow and power. The goodness of the performed fittings obtained with the circuit was checked by reducing $\chi^{2}$ to values smaller than $1.2 \times 10^{-3}$. Good agreement between sample repetitions was found.

$\mathrm{Li}_{4} \mathrm{Ti}_{5} \mathrm{O}_{12}$ (LTO) thin film electrodes of $200 \mathrm{~nm}$ thickness were deposited by RF-sputtering from a 4" target (Neyco, 99.5\% purity). The deposition was done under Ar flow of $25 \mathrm{sccm}$. The layers are 
deposited in the Pt base substrate. Due to their initial amorphous state, the LTO samples are heat-treated for $20 \mathrm{~min}$ at $800^{\circ} \mathrm{C}$ in oxygen atmosphere to make them crystalline and electrochemical active. The thickness of the films was determined by SEM and profilometry. Subsequently the LiPON solid electrolyte is deposited at different temperatures. Finally, Lithium metal anode is thermally evaporated using a home-made evaporation set-up inside an Ar glovebox. During Li deposition the pressure was kept at $10^{-5}$ Torr. The thickness of the film is monitored by a quartz crystal microbalance (SQM 160, Inficon). Cyclic voltammetry and galvanostatic charge-discharge experiments were carried out in an $\mathrm{Ar}$ glovebox $\left(\mathrm{O}_{2}, \mathrm{H}_{2} \mathrm{O}<1 \mathrm{ppm}\right)$ using a two-electrode home-made setup consisting of a spring loaded pin contacting the top Lithium anode electrode and a fixed clamp contacting the Pt current collector to the cathode electrode. A Methrom Autolab potentiostat and Nova software were employed for data collection.

\section{RESULTS AND DISCUSSION}

\section{$\underline{\text { LiPON solid electrolyte }}$}

The ionic conductivity of LiPON thin films reduces as the deposition temperature increases. Figure 1 shows the ionic conductivities obtained for $150 \mathrm{~nm}$ LiPON layers in a MEM configuration deposited at temperatures ranging from RT-to- $285{ }^{\circ} \mathrm{C}$. The increasing deposition temperature causes the ionic conductivity to fall by several orders of magnitude. The ionic conductivity decreases from $0.6 \mu \mathrm{S} \mathrm{cm}^{-1}$ at RT down to $0.002 \mu \mathrm{S} \mathrm{cm}^{-1}$ at $285{ }^{\circ} \mathrm{C}$. This result is in contrast with what has been presented in previous studies. $^{25,26}$ Jacke et al. reported in 2011 the first LiPON layers with increased ionic conductivity when deposited at temperatures of 200 and $300{ }^{\circ} \mathrm{C}$. This improvement in conductivity was related to the increasing amount of nitrogen content in their films (or decreasing amount of bridging oxygen) when increasing the deposition temperature. An opposite behavior was observed in a later study in which a decrease of $\mathrm{N}$ content with temperature was observed. ${ }^{29}$ Recently, Mani et al. ${ }^{25}$ showed an increasing ionic conductivity as LiPON deposition temperature increases applying a substrate bias during deposition of $10 \mathrm{~W}$. They obtained a rather high ionic conductivity $\left(9.8 \times 10^{-6} \mathrm{~S} \mathrm{~cm}^{-1}\right)$ at a deposition temperature of $500{ }^{\circ} \mathrm{C}$. This high ionic conductivity has been achieved before by Chiu et 
al. ${ }^{30}$ for room temperature depositions by adjusting also the bias power and applying a post-annealing treatment. These studies might indicate that ionic conductivity is more prone to increase by applying a bias power during deposition rather than deposition temperature changes. Moreover, it is important to notice that no temperature calibration of the apparatus is mentioned in any of the related works, thus a comparison between studies on the effective temperatures may be uncertain. Figure $1 \mathrm{~b}$ shows the typical Arrhenius behavior for the ionic conductivity values for all as-deposited LiPON layers and LiPO reference measured at different temperature points. The activation energies obtained for an as-deposited LiPON and LiPO layer are 0.58 and $0.61 \mathrm{eV}$, respectively.
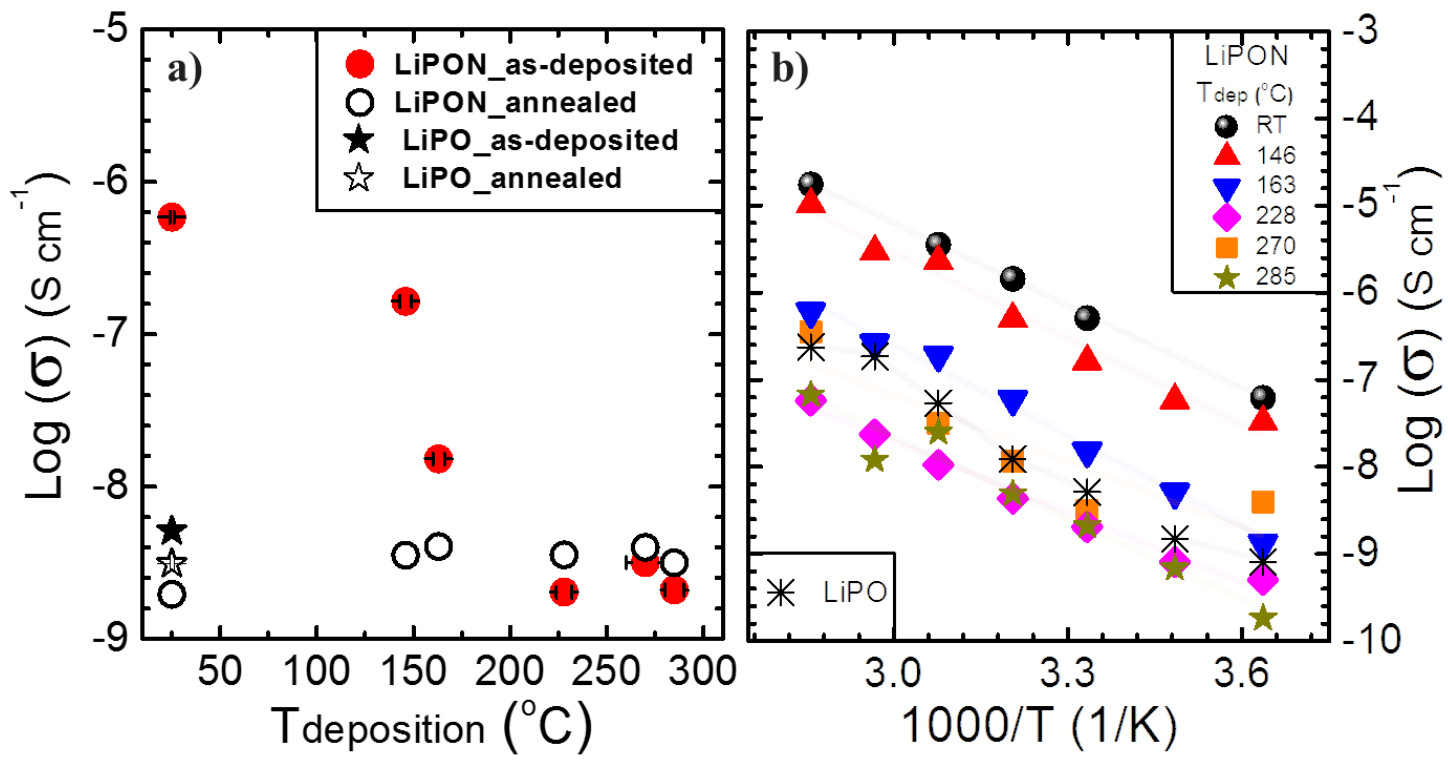

Figure 1: a) Temperature dependence of the ionic conductivity for $150 \mathrm{~nm}$ LiPON thin films. The filled and opened circles represent the $\sigma$ for the as-deposited and post-annealed layers at $350^{\circ} \mathrm{C}$ for 1 hour, respectively. The LiPO conductivity at RT for as-deposited and post-annealed films are shown as reference (stars). b) Arrhenius plot comparing the specific conductivity of the LiPON films deposited at different deposition temperatures. LiPO deposited at room temperature is shown as reference.

It is well known that the ionic conductivity of LiPON layers is linked to its stoichiometry. Up to date, composition of LiPON films vary extensively with no strong correlation of the ionic conductivity with simply $\mathrm{N}$ content variations. Hausbrand et al. reported similar ionic conductivities for films with 
different $\mathrm{N}$ concentration showing that reasonable conductivities can be achieved over a wide range of LiPON compositions. ${ }^{29}$ The composition of LiPON depends on the preparation method employed. Only LiPON films deposited by RF-sputtering already have a spread of $\mathrm{Li}_{2.14-3.3} \mathrm{PO}_{1.69-3.9} \mathrm{~N}_{0.16-1.39}$ with ionic conductivity values from 0.1 to $10 \mu \mathrm{S} \mathrm{cm}^{-1}$. To investigate the effect of the deposition temperature ( $\left.\mathrm{T}_{\mathrm{dep}}\right)$ on the composition of LiPON, thin films were analyzed by means of ERD. Composition of LiPON thin films as a function of $\mathrm{T}_{\text {dep }}$ varies within $5 \%$. The lowering of the ionic conductivity of LiPON thin films do not show any correlation with the layers element composition as $T_{\text {dep }}$ increases ERD depth profiles of a $50 \mathrm{~nm}$ LiPON thin film deposited at RT and $250^{\circ} \mathrm{C}$ are shown in Figure 2 a) and b), respectively. The depth profiles show no lithium out-diffusion from the LiPON films as showed by the sharp LiPON/TiN interface. The values of element concentration for all the different deposition temperatures are shown in Figure 2c. Contaminants such as $\mathrm{Si}, \mathrm{H}$ and $\mathrm{C}$ are slightly present in the films surface corresponding to $3.1,1.6$ and $0.4 \%$, respectively, should not be taken accountable for the nearly 3 orders of magnitude change in ionic conductivity. Literature studies attribute the rise in ionic conductivity to the increase in $\mathrm{N}$ content, more specifically to the higher triply-to-double coordinated sites ratio $\left(\mathrm{N}_{\mathrm{t}} / \mathrm{N}_{\mathrm{d}}\right)$. In our case, while the nitrogen content slightly increases, the content of oxygen decreases. This can be an indication of the substitution of oxygen by nitrogen and hence could represent a possible explanation for an increase in ionic conductivity but not for the decrease observed here. In addition, the variations reported in literature which correspond to 2 orders of magnitude spread in ionic conductivity (from 0.1to-10 $\mu \mathrm{Scm}^{-1}$ ) are within $10 \%$ change in element concentration. In contrast, the change in ionic conductivity reported here corresponds to more than 2 orders of magnitude $\left(0.002\right.$-to- $\left.0.6 \mu \mathrm{Scm}^{-1}\right)$ which, according to literature, cannot be explained by a change in material compositions of less than 5 $\%$. In particular, H concentration change of $1.4 \%$, which is detected mainly at the LiPON surface, would not be enough for this radical change in ionic conductivity. We interpret the variation of the ionic conductivity with $\mathrm{T}_{\mathrm{dep}}$ to a merely change in the glass structure of the LiPON electrolyte. In addition, XPS measurements show that the ratio between $\mathrm{N}_{t} / \mathrm{N}_{\mathrm{d}}$ increases with higher temperatures achieving a maximum at around $\mathrm{T}_{\text {dep }}=250{ }^{\circ} \mathrm{C}$ (See Fig. S2). This as well, does not support the view that ionic conductivity merely increases with increasing nitrogen content, especially with triply coordinated sites. 


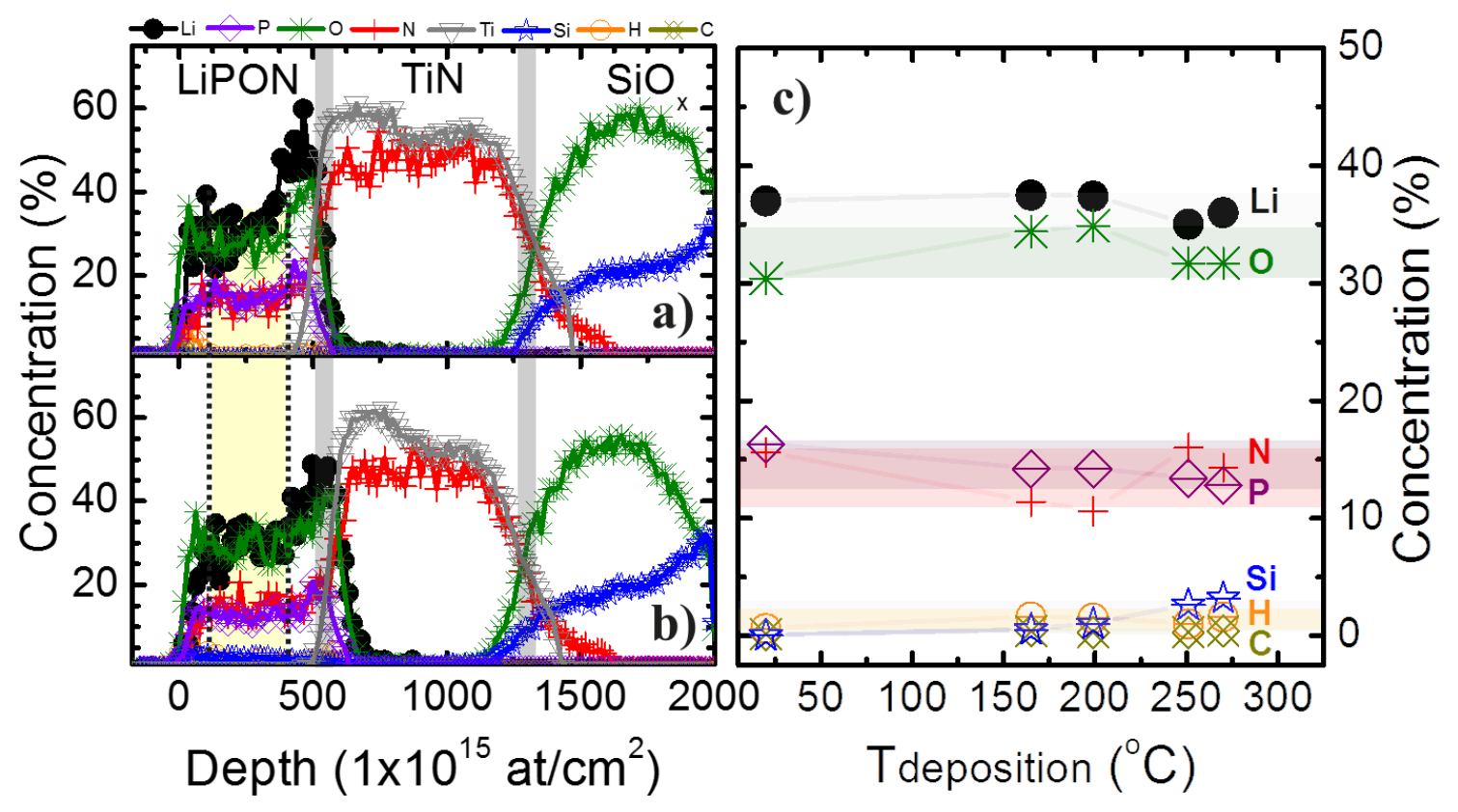

Figure 2: ERD depth profiles of a $50 \mathrm{~nm}$ LiPON layer deposited at a) room temperature and b) $250^{\circ} \mathrm{C}$ on a $70 \mathrm{~nm}$ TiN / $100 \mathrm{~nm}$ SiOx substrate. c) Concentration of the different elements existing in the LiPON layers as a function of deposition temperature. Values are the result from the integration of the ERD depth profiles indicated by the yellow zone in plots a) and b).

Structural differences in glasses may arise from the competition between kinetic and thermodynamic controlled configurations resulting in increased density and higher kinetic and thermodynamic stability when operating at an optimum state between surface mobility and deposition temperature. ${ }^{31}$ It has been found that when glasses are created by physical vapor deposition (PVD) at a temperature which is equivalent to $0.85 \mathrm{~T}_{\mathrm{g}}$ (being $\mathrm{T}_{\mathrm{g}}$ the glass transition temperature of the material) they acquire a substantial increase in thermal stability, increase in density, higher resistance to vapor uptake, among other improvements..$^{32,33,34}$ These new class of materials are known as highly stable glasses (HSG) and are generalized to a wide range of materials, such as small organic molecules, ${ }^{35}$ mixtures,${ }^{36}$ metallic alloys, ${ }^{37}$, polymers,.$^{38}$ and some alkyl phosphates. ${ }^{39}$ In addition, HSG properties have been reported through computer simulations for both organic and metallic systems. ${ }^{40}$ Hence, it could be also expected that HSG properties can be achieved in inorganic glass solid electrolytes like LiPON. HSG's have also shown that they can have higher crystallization temperatures when compared to their ordinary counterparts. Crystal growth can be about $30 \%$ faster in conventional liquid-cooled glasses compared to HSG's. ${ }^{41}$ 
In order to investigate the possible formation of highly stable LiPON glasses, we have determined the crystallization temperature $\left(\mathrm{T}_{\mathrm{c}}\right)$ of LiPON films deposited at different temperatures by means of in-situ XRD experiments. The results are reported in Figure 3. The crystallization temperature of the LiPON thin films increases by at least $150{ }^{\circ} \mathrm{C}$ when deposited at higher temperatures. A heating rate of $10{ }^{\circ} \mathrm{C}$ $\min ^{-1}$ was used under $\mathrm{He}$ over a $20^{\circ} 2 \theta$ window centered between $15^{\circ}$ and $35^{\circ}$ range. Typical in-situ XRD results are shown in Fig. $3 \mathrm{~b}$ as a color mapping of intensities for a LiPON sample deposited at RT. The crystallization temperature onsets discussed here are selected from the peak present at around $21.42^{\circ}-22.57^{\circ}$. Initially, all deposited LiPON thin films up to a substrate temperature of $285^{\circ} \mathrm{C}$ show to be amorphous. The results presented here show that the crystallization onset is dependent on $\mathrm{T}_{\text {dep }}$. At a deposition temperature of $270{ }^{\circ} \mathrm{C}$ no $\mathrm{T}_{\mathrm{c}}$ was observed up to $900^{\circ} \mathrm{C}$, meaning that at $\mathrm{T}_{\mathrm{dep}}=270{ }^{\circ} \mathrm{C}$ the LiPON film shows high stability against crystallization, about at least $150{ }^{\circ} \mathrm{C}$ higher than a $\mathrm{T}_{\mathrm{dep}}=\mathrm{RT}$ LiPON glass. This is consistent with a slower crystal growth for a highly thermally stable glass where the growth rate is related to the surface mechanism and the stability of its adjacent regions. The same experiments were done by heating the samples in air (not shown) where changes are detected at $27.5^{\circ}$ angle and seem to worsen as the temperature increases. This traces show the effects of $\mathrm{Li}_{2} \mathrm{CO}_{3}$ formation in LiPON when heating in air. This is not present when measuring under He (Fig. 3b). Thus, all measurements to determine $T_{c}$ and $T_{g}$ are done under He to avoid any influence of external factors such as moisture.

In agreement with our findings, $\mathrm{Aji}$ et $\mathrm{al} .{ }^{42}$ have reported that the thermal stability of a metallic glass created by RF-magnetron sputtering can be dramatically enhanced by depositing at higher temperatures. In their study, they reveal an increase of the crystallization temperature of $200 \mathrm{~K}, 0.5 \%$ increase in density and 30\% higher hardness and elastic modulus. This proves that materials created by means of RF-sputtering can attain different properties without a change in composition but merely with changes in their structure when employing different deposition rates and temperatures. The LiPON thin films created here at higher $T_{\text {dep }}$ show that $T_{c}$ can be delayed and can be estimated to slow down by at least $20 \%$, similar to what has been observed for highly stable organic glasses. ${ }^{41}$ In addition, mechanical properties seem to be another indication of highly stable glass formation. The mechanical properties of 
LiPON layers with different $\mathrm{N}$ concentrations have been studied by Li et al. ${ }^{14,43}$. In their work they established that the elastic modulus of the films increases with increasing $\mathrm{N}$ content as well as for ionic conductivity. Elastic modulus can be affected not only by compositional changes in glasses but as well as by preparation conditions as mentioned before. The results presented here show that as $\mathrm{T}_{\text {dep }}$ increases for the LiPON layers there is a decrease in ionic conductivity and increase in thermal stability. This can bring changes in density and elastic modulus. Since the ionic conductivities obtained here do not show any relation with $\mathrm{N}$ concentration we may infer that the increase in ionic conductivity reported by Li et al. ${ }^{43}$ comes mainly from an increase in elastic moduli and is not directly related to the $\mathrm{N}$ content itself. In addition, it has been proved in other studies that a decrease in film density in boron sub-oxide thin films causes also an elastic modulus reduction. ${ }^{44}$ Hence, ionic conductivity might be more linked into the local structure and density of the material and not only to $\mathrm{N}$ content. Highly stable glasses present very little variations in density and might be difficult to establish for LiPON. Although elastic modulus changes could be possibly detected, it was not the main focus of this work. On a later study, Hausbrand et al. ${ }^{29}$ discussed the mechanism by which $\mathrm{N}_{2}$ is incorporated in the structure of $\mathrm{Li}_{3} \mathrm{PO}_{4}$ to create $\mathrm{LiPON}$ and how composition can be widely scattered depending on the preparation method and deposition parameters such as power, pressure and substrate temperature. In their study, LiPON composition is obtained via XPS up to substrate temperatures of $300^{\circ} \mathrm{C}$. Their LiPON films show a significant increase of $\mathrm{Li}$ and a decrease of $\mathrm{N}$ as the deposition temperature increases. Although they do not report ionic conductivity values the correlation between composition and deposition temperature is in contrast to previous studies by Jaegermann and coworkers. ${ }^{26}$ This, together with the data reported here suggest that the large scattering in ionic conductivity with identical chemical composition could be explained by structural variations. These variations imply structural reconfigurations which can be achieved by the competition between surface mobility and temperature during film growth. In addition, glasses may still suffer from short-range order differences in the amorphous state. ${ }^{45}$ Short-range order is affected with the incorporation of nitrogen itself consequently lowering of phosphate chains length while still obtaining both triply $(-\mathrm{N}<)$ and doubly $(-\mathrm{N}=\mathrm{P}-)$ coordinated nitrogen bonds. Considering that the compositional values obtained here for all amorphous LiPON thin films grown at different $T_{\text {dep }}$ do not change dramatically and the observed shift to higher crystallization temperatures indicates a possible 
modification in the short-range order of the LiPON structure. This structural changes may alter Li-ion diffusion within the solid electrolyte layer and might be the main responsible for the lowering in ionic conductivity.
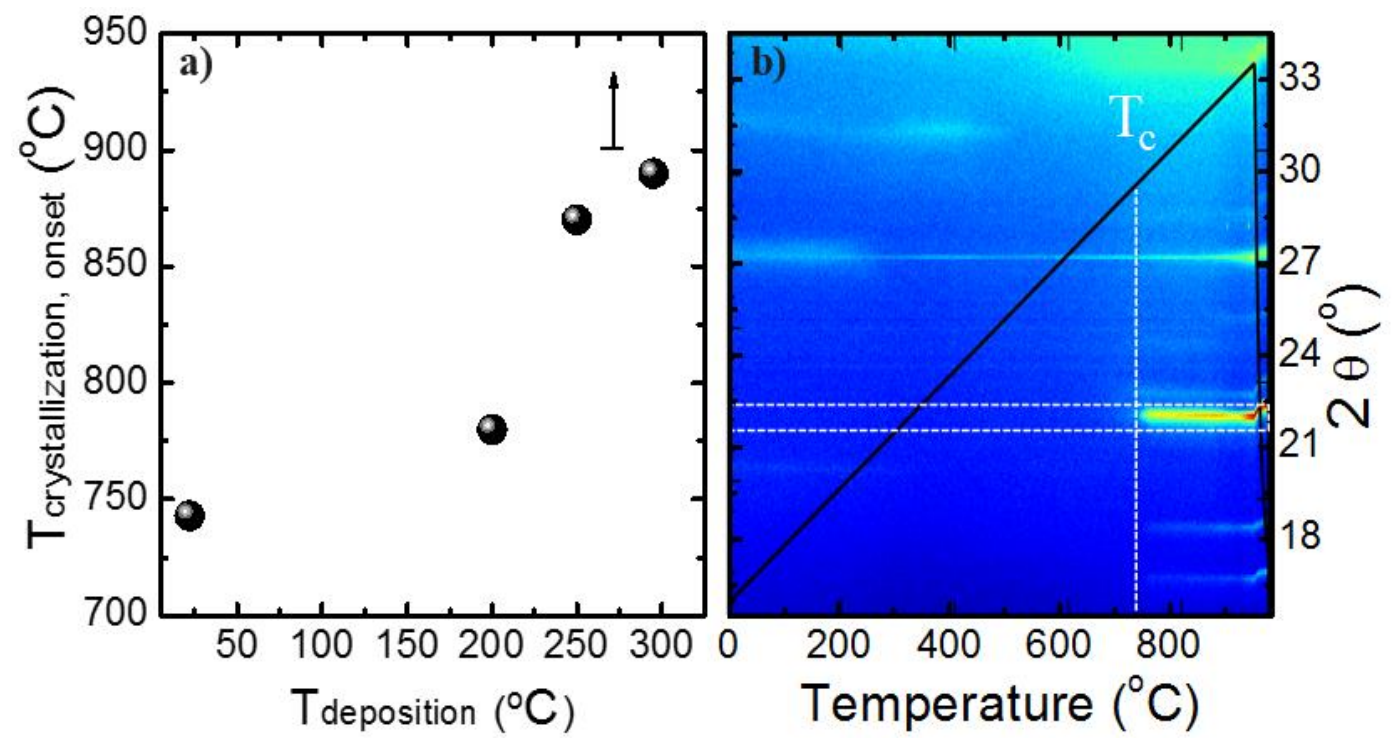

Figure 3: a) Temperature onset of crystallization for LiPON thin films as a function of deposition temperature obtained from in-situ XRD in the $21.42^{\circ}-22.57^{\circ}$ window. b) Typical in-situ XRD mapping in the $2 \theta$ range of $15-35^{\circ}$ using a heating rate of $10^{\circ} \mathrm{C} /$ min between room temperature and $985^{\circ} \mathrm{C}$.

Ionic migration in solid electrolytes can exploit several mechanisms. The first type, which is the most common for lithium ions due to their small size, is related to the motion across vacancies or interstitials. Diffusion process in amorphous solids can be quite complex compared to crystalline materials and ion conduction can be governed by a combination of mechanisms. In a recent study, Sicolo et al. claim that $\mathrm{Li}^{+}$interstitials are energetically preferred over vacancies since they are more abundant and mobile. ${ }^{46}$ Good electrolytes must have a sufficient number of vacancies and interstitials in their structure and low activation energies in order to have large enough ionic conductivity. Vacancies and interstitials sites are defect modes inside the structure of a material. A highly dense packed glassy material would have a reduction in the available vacancies present in its structure. In the view of highly stable glassy materials, Ediger and coworkers have shown that an amorphous material may suffer important structural changes when the deposition is created by PVD using $\mathrm{T}_{\mathrm{dep}}=0.85 \mathrm{~T}_{\mathrm{g}}$. At this temperature higher surface mobility 
allows the glass to efficiently rearrange into a material with low enthalpy and high stability. The network of a glassy system has found to change upon deposition temperature. Anisotropy and higher density is one of the properties of highly stable glasses. ${ }^{47,48}$ It has been shown that enhancement in kinetic stability in these materials is correlated to the structure orientation. Glassy network that shows a sandwiched-like layering (lying plane to the substrate) can show to be more stable. Sicolo et al. ${ }^{46}$ studied the structure of LiPON by Density Functional Theory calculations obtaining sandwich-like amorphous structures with alternating Li-rich and Li-poor layers implying an anisotropic Li-transport in the LiPON solid electrolyte which is correlated with the local configuration in the glassy network. It seems that LiPON exhibits most of the properties that can be tuned in a highly stable glass, thus its preparation in a higher thermal and kinetic stable state is most likely to be obtained. In addition, vacancies and interstitials will decay as a more well-packed material is formed, thus a lowering in the ionic conductivity can be expected supposing that the composition of the material does not differ drastically. This view is supported by the results presented here. A second mechanism involved in ionic migration is less common and typically called knock-on, since the ions are able to displace neighboring atoms to find their path. HSG's have shown to withstand higher temperatures since their packing arrangement is highly efficient. Highly dense and well packed structures will show more resistance to displacements of neighboring atoms. Highly stable glasses need mobile sites in order to unravel such displacements. ${ }^{34}$ If such mobile sites are not present, ionic conduction would be hard to establish and an ionic conductivity reduction should be expected.

An important property of amorphous materials is the temperature at which the structure changes from a brittle to a non-crystalline ductile glass network during heating. This is known as the glass transition temperature $\left(\mathrm{T}_{\mathrm{g}}\right)$. For bulk LiPON, $\mathrm{T}_{\mathrm{g}}$ has been reported ranging from $\mathrm{T}_{\mathrm{g}}=300-350{ }^{\circ} \mathrm{C}$ depending on the preparation method and composition..$^{18,49,50}$ Here, in-situ ellipsometry was used to detect the onset temperature of the glass transition for thin film LiPON samples deposited at different substrate temperatures. Ellipsometry is a powerful optical technique that can non-destructively determine the thickness of the samples and thus, can also be employed to detect the thickness change during the glass transition when applying a heating ramp by measuring the polarization of the reflected light. Figure 4 
shows the thickness variation recorded for samples deposited at different temperatures using a heating ramp of $10^{\circ} \mathrm{C} \mathrm{min}^{-1}$ under He. The onset temperature $\left(\mathrm{T}_{\text {onset }}\right)$ detected for each sample was $219^{\circ} \mathrm{C}, 263$ ${ }^{\circ} \mathrm{C}$ and $281{ }^{\circ} \mathrm{C}$ for the samples deposited at RT, $215^{\circ} \mathrm{C}$ and $270{ }^{\circ} \mathrm{C}$, respectively. It can be clearly seen that the onset of the glass transition depends upon the deposition temperature. It is known that $T_{g}$ is clearly influenced by the chemistry of the glass and its structure. Since the LiPON samples prepared here do not show any significant change in composition we deduce that these changes in onset temperature are determined merely from changes in the glass network as already suggested from the insitu XRD measurement. Since measurements are performed under He, also no effects due to moisture are expected. In the vision of highly stable glasses it appears that depositions at higher temperatures makes LiPON to probe more stable configurations achieving a more highly packed network. This material can withstand higher temperatures before breaking network bonds at $\mathrm{T}_{\mathrm{g}}$. Detailed studies on the dependence of the dynamic glass transition upon temperature would need to be performed in order to quantify the level of stability of LiPON glasses. Nevertheless, it is clear that highly thermally stable LiPON glasses are obtained. For the LiPON sample deposited at RT (Fig. 4a), data fitting to the 3 layer model was unsuccessful at higher temperatures. This is probably due to the rapid crystallization of the film just after $\mathrm{T}_{\text {onset. }}$ This rapid crystallization is not clearly visible in the in-situ XRD experiments shown in Figure 3 in the $2 \theta$ window between $21.42^{\circ}-22.57^{\circ}$. It is known that lithium phosphorus glass systems can attain different crystallization phases such as $\mathrm{LiPO}_{3}, \mathrm{Li}_{3} \mathrm{PO}_{4}$ and $\mathrm{Li}_{4} \mathrm{P}_{2} \mathrm{O}_{7}{ }^{51}$ This can lead to different $\mathrm{T}_{\mathrm{c}}$ detections for the samples presented here. 


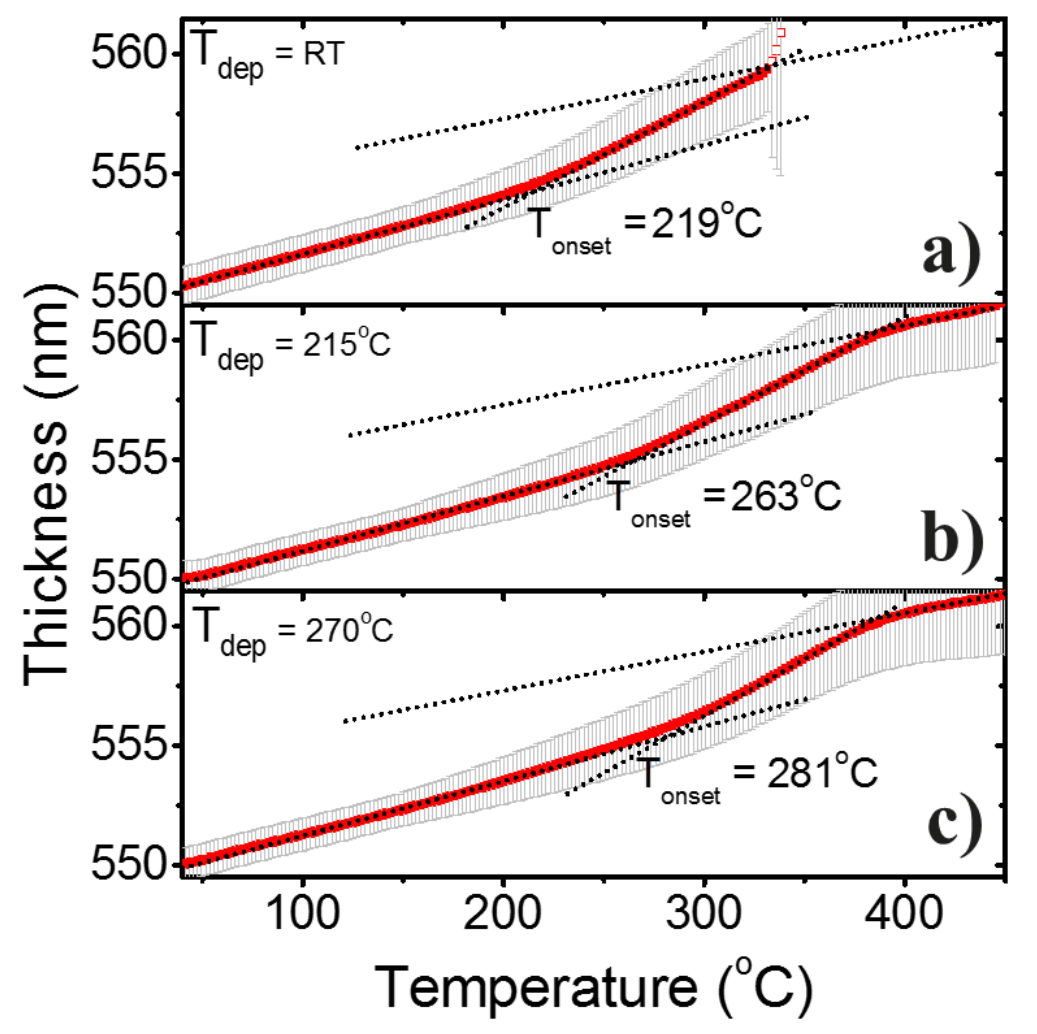

Figure 4: In-situ ellipsometry measurements for $550 \mathrm{~nm} \mathrm{LiPON}$ layers deposited at RT, $215{ }^{\circ} \mathrm{C}$ and $270{ }^{\circ} \mathrm{C}$ on a $100 \mathrm{~nm} \mathrm{SiO}$ substrate. A heating ramp of $10{ }^{\circ} \mathrm{C} \mathrm{min}{ }^{-1}$ was used to track the thickness change present in the onset of the glass transition.

The glass transition temperature defined of thin film LiPON glass layers reported here is $\mathrm{T}_{\mathrm{g}}=219{ }^{\circ} \mathrm{C}$. This value seems somehow lower with respect to the ones reported for bulk LiPON samples. It is known that materials may suffer from size effects and a shift to lower temperatures of the glass transition can be observed for thin film samples when compared to their bulk counterpart. This can be applied to the case of thin film LiPON layers. Although more experiments need to be performed in order to clearly determine size effects present in LiPON, this it is not the main scope of this study.

The properties of a glass depends on its thermal history. When a glass is annealed above $\mathrm{T}_{\mathrm{g}}$ the thermal history is "erased" and an ordinary glass system can be obtained when cooling at a fixed rate. Here, thin film LiPON samples created at different substrate temperatures are post-annealed at $350{ }^{\circ} \mathrm{C}$ for $1 \mathrm{hr}$ in Argon in order to see the effect on the glassy structure and hence ionic conductivity. The annealing temperature here is above the obtained $\mathrm{T}_{\mathrm{g}}$ value. At this temperature the structural relaxation time of 
LiPON would be faster and hence the same glass structure will be obtained for all samples. Consequently, such material homogenization at high annealing temperatures is expected to result in similar ionic conductivity, independently of the deposition temperature of the sample. In Figure 1a the ionic conductivity values are plotted for samples which have been post-annealed. These are represented by the black stars in Fig. 1a. The values of an as-deposited and a post-annealed $\mathrm{LiPO}_{3}$ thin film is shown as reference. It can be seen that all samples independent of their initial ionic conductivity values reach a steady conductivity after annealing of $\sim 4 \times 10^{9} \mathrm{~S} \mathrm{~cm}^{-1}$ in the region where $\mathrm{LiPO}_{3}$ conductivity is obtained. XRD shows that LiPON samples post-annealed still attain its amorphous structure (See Fig. S3). The effect of post-annealing treatments have also been studied on LiPON films. Li et al. reported an enhancement of ionic conductivity when LiPON was heat treated at $200{ }^{\circ} \mathrm{C}$ for $1 \mathrm{hr}$ as opposed to our results. ${ }^{20}$ This discrepancy between the results can be explained by considering that the properties of glasses when annealed below or above the glass transition can have notorious differences. These differences would then affect $\mathrm{Li}$-ion transport in the structure. ${ }^{52} \mathrm{Li}$ and coworkers did not report any values for $\mathrm{T}_{\mathrm{g}}$ of LiPON. Therefore, in order to clarify these differences between the two works, we can suppose that the annealing temperature used in their experiments is below $\mathrm{T}_{\mathrm{g}}$ affecting the glassy network differently than what is reported here. For a better understanding of the effect that these LiPON layers have on thin film battery performance we have fabricated all solid state battery stacks based on $\mathrm{Li}_{4} \mathrm{Ti}_{5} \mathrm{O}_{12}$ cathode electrode and $\mathrm{Li}$ metal anode.

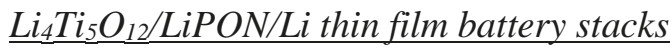

The effect of LiPON thin film solid electrolyte deposited at different temperatures was investigated in a full all-solid state battery based on $\mathrm{Li}_{4} \mathrm{Ti}_{5} \mathrm{O}_{12}$ cathode and $\mathrm{Li}$ metal anode. LTO can intercalate three $\mathrm{Li}+$ ions into its spinel structure at $1.55 \mathrm{~V}(\mathrm{vs} \mathrm{Li}+/ \mathrm{Li})$, it has a negligible volume expansion during operation $(0.3 \%)$ between 1.0 and $2.0 \mathrm{~V}(\mathrm{vs} \mathrm{Li}+/ \mathrm{Li})$ and possesses good $\mathrm{Li}+$ ion insertion/extraction reversibility and excellent cycling performance. LTO is considered to have low electronic conductivity $\left(10^{-12} \mathrm{~S} / \mathrm{cm}\right)$ which may limit its performance at high C-rates. ${ }^{53}$ 
Here, we have fabricated six solid state thin film battery stacks using $200 \mathrm{~nm}$ LTO cathode, $550 \mathrm{~nm}$ $\mathrm{LiPO}(\mathrm{N})$ solid electrolyte and $1 \mu \mathrm{m} \mathrm{Li} \mathrm{metal} \mathrm{anode.} \mathrm{The} \mathrm{LiPON} \mathrm{solid} \mathrm{electrolyte} \mathrm{for} \mathrm{the} \mathrm{different} \mathrm{cells}$ is deposited at $\mathrm{RT}, 182{ }^{\circ} \mathrm{C}, 213{ }^{\circ} \mathrm{C}, 238{ }^{\circ} \mathrm{C}$ and $260{ }^{\circ} \mathrm{C}$. $\mathrm{LiPO}_{3}$ solid electrolyte is deposited at room temperature. Figure 5a shows the cyclic voltammograms of these LTO-based batteries at a scanning rate of $10 \mathrm{mV} \mathrm{s}^{-1}$ in a voltage range between $0.8 \mathrm{~V}$ and $2.5 \mathrm{~V}$ where the typical $\mathrm{Li}+$ extraction/insertion peaks are observed at an average potential of $1.55 \mathrm{~V}\left(\mathrm{vs} . \mathrm{Li}^{+} / \mathrm{Li}\right)$. It is clearly observed that there is a kinetic limitation in the solid state cell depending on the LiPON $\mathrm{T}_{\text {dep }}$. The cathodic peak shifts from $1.72 \mathrm{~V}$ to $1.82 \mathrm{~V}$ while the anodic peak shifts from $1.46 \mathrm{~V}$ to $1.34 \mathrm{~V}$ as the LiPON $\mathrm{T}_{\text {dep }}$ increases. A shoulder peak is also noticeable at higher potentials $(\sim 2.1 \mathrm{~V})$ indicating other possible phase formations or interface effects in the electrode/electrolyte region. For comparison a LTO-based battery using $\mathrm{LiPO}_{3}$ solid electrolyte shows a cathodic and anodic peak at $2.04 \mathrm{~V}$ and $1.25 \mathrm{~V}$, respectively. The shifts in the redox potential and the broadening of the peaks can be explained by the increase in charge transfer resistance of the cell due to the creation of a limited lithium transport interface, by the limiting ionic conductivity at higher LiPON deposition temperatures and/or by side reactions happening in the active materials. Figure S4 shows the cell resistance as a function of LiPON deposition temperature as well as the cycling stability of the cells at $10 \mathrm{C}\left(120 \mu \mathrm{Ah} \mathrm{cm}^{-2}\right)$.
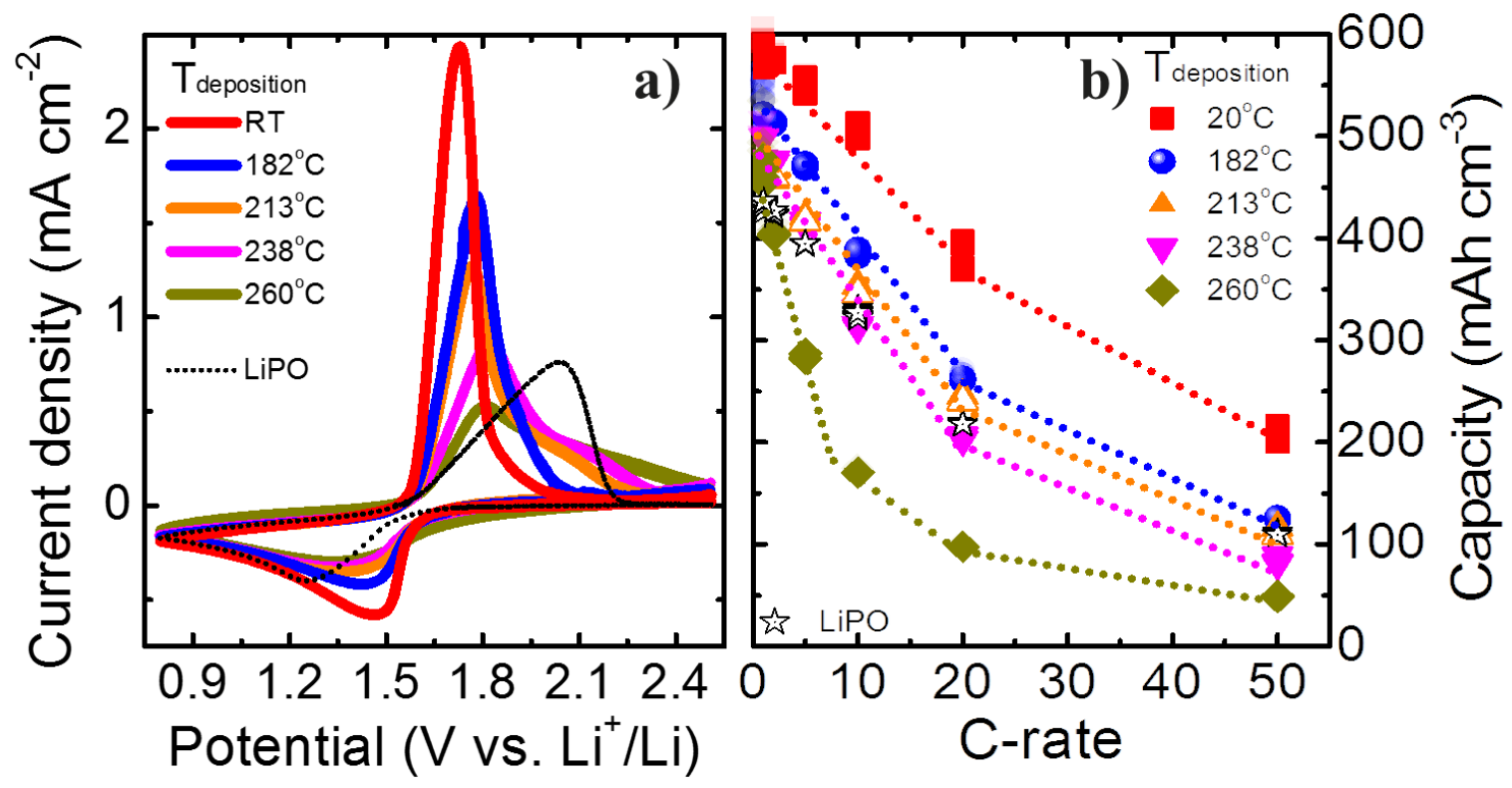

Figure 5: a) Cyclic voltammograms at a scanning rate of $10 \mathrm{mV} \mathrm{s}^{-1}$ for a thin film all-solid state battery stack based on $\mathrm{Li}_{4} \mathrm{Ti}_{5} \mathrm{O}_{12} / \mathrm{LiPON} / \mathrm{Li}$ using LiPON electrolyte deposited at different temperatures. b) C-rate performance for the same battery stacks at rates from 1-50 C. Battery stack using LiPO as electrolyte deposited at RT is shown as reference. 
Figure $5 \mathrm{~b}$ shows the $\mathrm{C}$-rate dependence based on galvanostatic charge/discharge process of the different LTO-based batteries. The charge/discharge process was performed on a voltage window between 0.8 $\mathrm{V}$ and $2.5 \mathrm{~V}$ at C-rates between $1-50 \mathrm{C}$. It can be noticed that the C-rate performance becomes sluggish as the LiPON $\mathrm{T}_{\text {dep }}$ increases. It has been shown that the LiPON layers presented here exhibit a reduction in ionic conductivity as $\mathrm{T}_{\text {dep }}$ increases. This lower ionic conductivity limits the performance of the cells significantly at higher C-rates. Other effects such as blocking interfaces that might be present can also have an effect on battery performance. The cathode/electrolyte interface seem to be one of the main limiting factors for lithium transport. ${ }^{54}$ This reduced performance of the battery stacks with increasing deposition temperature is expected since such LiPON layers are characterized by lower ionic conductivity.

ERD shows no significant changes in the composition of as-deposited electrode and electrolyte layers when LiPON is deposited at high temperature. Previously it has been shown that interfaces limit lithium transport significantly in solid state batteries. Decrease lithium concentration in cathode/electrolyte interfaces have been observed in as-deposited films while lithium accumulation is seen during the delithiation process. ${ }^{54}$ In an attempt to detect interface effects and its relation to the LiPON deposition temperature ERD was performed on LiPON/LTO stacks. Figure 6a shows the ERD depth profile composition analysis for a half stack cell consisting of $100 \mathrm{~nm}$ LiPON layers deposited at RT and 215 ${ }^{\circ} \mathrm{C}$ on top of a $100 \mathrm{~nm}$ LTO electrode using Pt as substrate. Changes in lithium concentration in the electrode/electrolyte interface cannot be detected. For as-deposited films the lithium concentration seem to be constant in the materials and no abrupt decrease or accumulation is observed in the interface for all elements, as evident from table 1. Figure $6 \mathrm{~b}$ shows a cross section SEM image of a complete battery stack consisting of $200 \mathrm{~nm}$ LTO, $550 \mathrm{~nm}$ LiPON and $1 \mu \mathrm{m}$ Lithium where sharp interfaces can be observed. There are composition differences between LiPON samples used between MEM architectures and electrolyte/electrode half stacks. A lower concentration of Li and $\mathrm{N}$ are obtained for as-deposited samples (Table 1). The lower Li concentration in the LiPON may be an indication of Li diffusing into the electrode material. This is confirmed by the composition values for LTO which have higher Li 
concentrations than the expected spinel $\mathrm{Li}_{4} \mathrm{Ti}_{5} \mathrm{O}_{12}$ structure. Nitrogen implantation might also occur in reactive sputtering processes using $\mathrm{N}_{2}$ atmosphere which is the process used here to deposit the LiPON solid electrolyte. ${ }^{55}$ The lowering of $\mathrm{N}$ in the LiPON suggests $\mathrm{N}$ incorporation in the electrode by diffusion. N-doped LTO structures have shown to have enhanced lithium storage properties. ${ }^{56}$ Nitrogen is not detectable in the overall electrode concentration and even if $\mathrm{N}$ diffusion into the LTO electrode were present the lower ionic conductivity in LiPON and other interfacial effects would have dominated Li-ion transport.

Table 1. Composition of LiPON thin films deposited at different temperatures. a) $150 \mathrm{~nm}$ LiPON films deposited in TiN substrates b) $100 \mathrm{~nm}$ LiPON films deposited on LTO electrode.

\begin{tabular}{|c|c|c|c|c|}
\hline $\begin{array}{c}\text { Element } \\
\text { Tdep }\left({ }^{\circ} \mathrm{C}\right)\end{array}$ & $\mathrm{Li}$ & $\mathbf{P}$ & $\mathbf{O}$ & $\mathbf{N}$ \\
\hline $\mathrm{RT}$ & 2.27 & 1.00 & 1.87 & 0.96 \\
\hline 135 & 2.64 & 1.00 & 2.42 & 0.80 \\
\hline 146 & 2.63 & 1.00 & 2.46 & 0.75 \\
\hline 191 & 2.61 & 1.00 & 2.37 & 1.19 \\
\hline 245 & 2.81 & 1.00 & 2.48 & 1.12 \\
\hline
\end{tabular}

\begin{tabular}{|c|c|c|c|c|c|c|c|}
\hline Tdep $\left({ }^{\circ} \mathrm{C}\right)$ & $\mathrm{Li}$ & $\mathrm{P}$ & $\mathrm{O}$ & $\mathbf{N}$ & $\mathrm{Li}$ & $\mathrm{Ti}$ & $\mathrm{O}$ \\
\hline $\mathrm{RT}$ & 1.8 & 1.00 & 1.7 & 0.7 & 4.7 & 5.0 & 12.9 \\
\hline 213 & 1.8 & 1.00 & 2.0 & 0.6 & 5.0 & 5.0 & 12.1 \\
\hline
\end{tabular}

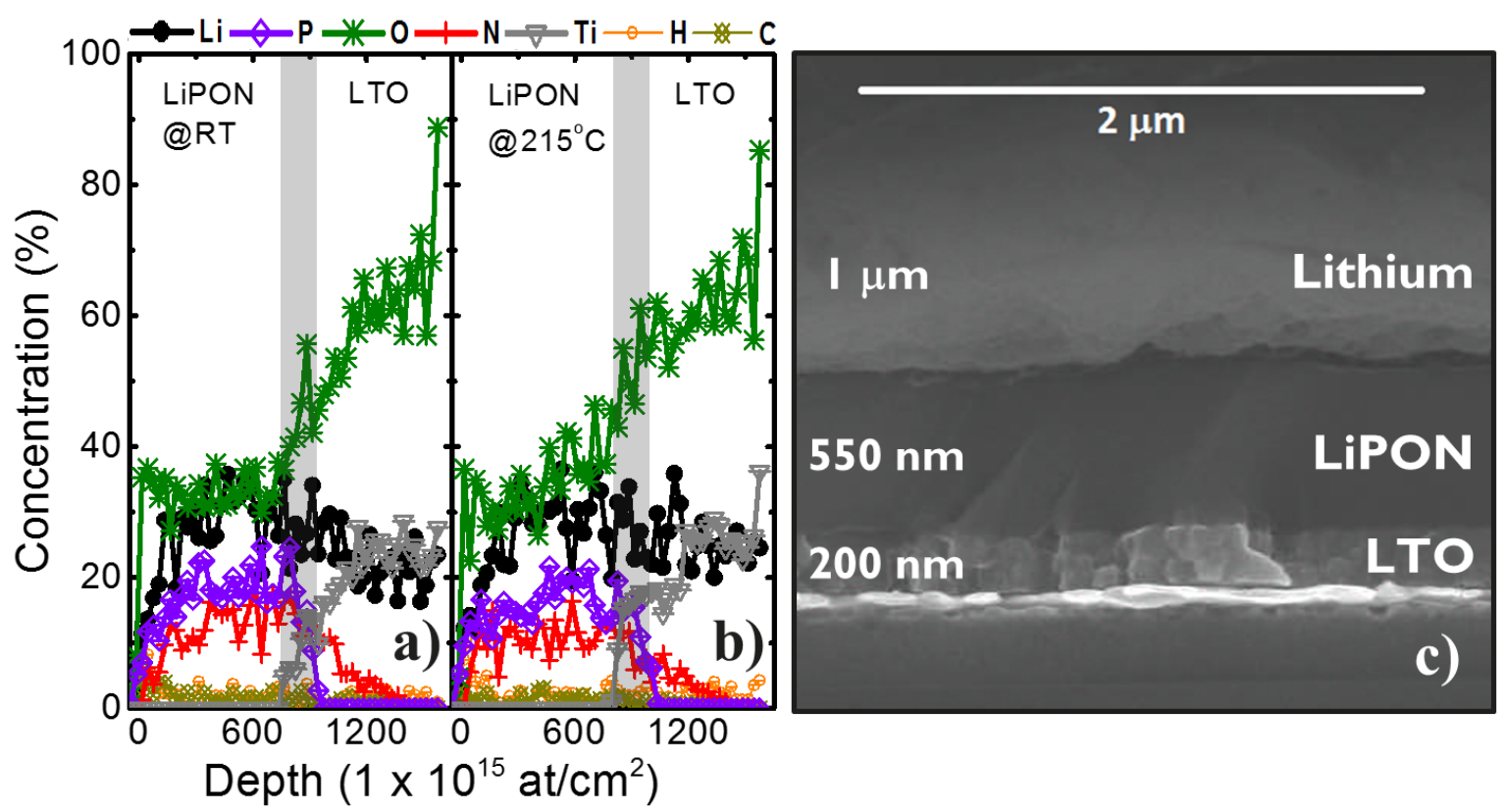

Figure 6: ERD depth profiles of a $100 \mathrm{~nm}$ LTO films with $100 \mathrm{~nm}$ LiPON layer deposited at a) room temperature and b) $215^{\circ} \mathrm{C}$ on a $70 \mathrm{~nm} \mathrm{Pt} / 70 \mathrm{~nm} \mathrm{TiO} / 100 \mathrm{~nm} \mathrm{SiOx}$ substrate. b) Cross section SEM image showing the full thin film all solid state battery with LiPON electrolyte deposited at room temperature and including the Li anode. 


\section{CONCLUSIONS}

Thin film solid state $\mathrm{Li}_{4} \mathrm{Ti}_{5} \mathrm{O}_{12}$-based batteries have been developed by using different solid electrolyte LiPON deposition temperatures by means of RF-sputtering. LiPON layers retain their amorphous character even when deposited at a higher temperature of $285^{\circ} \mathrm{C}$. The composition of the LiPON solid electrolyte seems to remain the same independently of deposition temperature. The ionic conductivity of LiPON decreases with increasing deposition temperature by nearly 3 orders of magnitude in contrast with previous reports. This is interpreted as the result of a change in the local structure of the glassy network of LiPON which makes $\mathrm{Li}+$ diffusion through vacancies and interstitials tougher to occur. This is related to the creation of a highly stable LiPON layer with a closed-packed structure which is attained at $\mathrm{T}_{\text {dep }}$ close to the glass transition temperature $\left(\mathrm{T}_{\mathrm{g}}\right)$. The thermal stability upon deposition temperature of thin film LiPON layers is studied by means of in-situ ellipsometry where $\mathrm{T}_{\mathrm{g}}$ is determined to be 219 ${ }^{\circ} \mathrm{C}$. As the $\mathrm{T}_{\text {dep }}$ increases the onset of the glass transition temperature occurs at higher temperatures implying an enhancement in thermal stability. In-situ XRD measurements corroborate this hypothesis since the crystallization temperature $\left(T_{c}\right)$ shifts to higher values as $T_{\text {dep }}$ increased. Therefore, it is possible to conclude that LiPON layers with a higher resistance to crystallization can be obtained. The reduced ionic conductivity of high temperature LiPON layers is shown to clearly affect the capacity and C-rate performance of the full thin film battery stack. The maximum attainable volumetric capacities obtained are decreased when using high temperature LiPON. The C-rate performance was determined for the thin film batteries and was found to be in good relation with the lowering of ionic conductivity. ERD performed on the electrode/electrolyte interface do not show substantial differences on material concentrations which can affect battery performance. Nevertheless this phenomenon cannot be excluded since it has been observed in other reports and it might be assessed with a higher detection limit technique. In addition, the LiPON composition changes slightly when deposited on the LTO electrode. Lower concentrations of Li and $\mathrm{N}$ can be observed in the as-deposited LiPON samples which may be an indication of Li diffusion and possible $\mathrm{N}$ incorporation in the electrode material upon deposition of the LiPON solid electrolyte. These results show that battery performance is largely 
affected by the LiPON solid electrolyte properties and by the possible interfacial effects when changing deposition parameters. These results show that the performance of thin film batteries can be drastically altered by having structural variations in the solid electrolyte film. Although ionic conductivity decreases worsening battery behavior, its thermal stability drastically enhances which might open new possibilities for high temperature applications.

\section{ACKNOWLEDGEMENTS}

This project has received funding from the EU Horizon 2020 research and innovation programme under the MSCA grant agreement No 658057. The authors thank Thomas Dobbelaere for the in-situ XRD measurements, Felix Mattelaer for the help provided with the in-situ ellipsometry technique and Johan Mersschaut for the ERD measurements.

\section{REFERENCES}

(1) Zhao, S.; Fu, Z.; Qin, Q. A Solid-State Electrolyte Lithium Phosphorus Oxynitride Film Prepared by Pulsed Laser Deposition. Thin Solid Films 2002, 415 (1-2), 108-113.

(2) Suzuki, N.; Shirai, S.; Takahashi, N.; Inaba, T.; Shiga, T. A Lithium Phosphorous Oxynitride (LiPON) Film Sputtered from Unsintered Li3PO4 Powder Target. Solid State Ionics 2011, 191 (1), 49-54.

(3) Tatsumisago, M.; Hayashi, A. Superionic Glasses and Glass - Ceramics in the Li 2 S - P 2 S 5 System for All-Solid-State Lithium Secondary Batteries. Solid State Ionics 2012, 225, 342345.

(4) Bates, J. B.; Dudney, N. J.; Gruzalski, G. R.; Zuhr, R. A.; Choudhury, A.; Luck, C. F.; Robertson, J. D. Fabrication and Characterization of Amorphous Lithium Electrolyte Thin Films and Rechargeable Thin-Film Batteries. J. Power Sources 1993, 43 (1-3), 103-110.

(5) Put, B.; Vereecken, P. M.; Meersschaut, J.; Sep??lveda, A.; Stesmans, A. Electrical Characterization of Ultrathin RF-Sputtered LiPON Layers for Nanoscale Batteries. ACS Appl. 
Mater. Interfaces 2016, 8 (11), 7060-7069.

(6) Yu, Xiaohua; Bates, J. B.; Jellison Jr., G. E.; Hart, F. X. A Stable Thin-Film Lithium Electrolyte: Lithium Phosphorus Oxynitride. J. Electrochem. Soc. 1997, 144 (2), 524.

(7) Knauth, P. Inorganic Solid Li Ion Conductors: An Overview. Solid State Ionics. 2009, pp 911916.

(8) Nowak, S.; Berkemeier, F.; Schmitz, G. Ultra-Thin LiPON Films - Fundamental Properties and Application in Solid State Thin Film Model Batteries. J. Power Sources 2015, 275, 144 150.

(9) Dudney, N. J. Addition of a Thin-Film Inorganic Solid Electrolyte (Lipon) as a Protective Film in Lithium Batteries with a Liquid Electrolyte. J. Power Sources 2000, 89 (2), 176-179.

(10) Su, Y.; Falgenhauer, J.; Polity, A.; Leichtweiß, T.; Kronenberger, A.; Obel, J.; Zhou, S.; Schlettwein, D.; Janek, J.; Meyer, B. K. LiPON Thin Films with High Nitrogen Content for Application in Lithium Batteries and Electrochromic Devices Prepared by RF Magnetron Sputtering. Solid State Ionics 2015, 282, 63-69.

(11) Put, B.; Mees, M. J.; Hornsveld, N.; Sepulveda, A.; Vereecken, P. M.; Kessels, W. M. M.; Creatore, M. Plasma - Assisted ALD of Lipo(N) for Solid State Batteries. ECS Trans. 2017, 75 (20), 61-69.

(12) Liu, W.-Y.; Fu, Z.-W.; Li, C.-L.; Qin, Q.-Z. Lithium Phosphorus Oxynitride Thin Film Fabricated by a Nitrogen Plasma-Assisted Deposition of E-Beam Reaction Evaporation. Electrochem. Solid-State Lett. 2004, 7 (9), J36.

(13) Vereda, F.; Clay, N.; Gerouki, A.; Goldner, R. .; Haas, T.; Zerigian, P. A Study of Electronic Shorting in IBDA-Deposited Lipon Films. J. Power Sources 2000, 89 (2), 201-205.

(14) Li, G.; Li, M.; Dong, L.; Li, X.; Li, D. Low Energy Ion Beam Assisted Deposition of Controllable Solid State Electrolyte LiPON with Increased Mechanical Properties and Ionic Conductivity. Int. J. Hydrogen Energy 2014, 39 (30), 17466-17472.

(15) Kozen, A. C.; Pearse, A. J.; Lin, C.-F.; Noked, M.; Rubloff, G. W. Atomic Layer Deposition of the Solid Electrolyte LiPON. Chem. Mater. 2015, 27 (15), 5324-5331.

(16) Nisula, M.; Shindo, Y.; Koga, H.; Karppinen, M. Atomic Layer Deposition of Lithium 
Phosphorus Oxynitride. Chem. Mater. 2015.

(17) Kim, H. T.; Mun, T.; Park, C.; Jin, S. W.; Park, H. Y. Characteristics of Lithium Phosphorous Oxynitride Thin Films Deposited by Metal-Organic Chemical Vapor Deposition Technique. J. Power Sources 2013, 244, 641-645.

(18) Muñoz, F.; Durán, A.; Pascual, L.; Montagne, L.; Revel, B.; Rodrigues, A. C. M. Increased Electrical Conductivity of LiPON Glasses Produced by Ammonolysis. Solid State Ionics 2008, $179(15-16), 574-579$.

(19) Carrillo Solano, M. A.; Dussauze, M.; Vinatier, P.; Croguennec, L.; Kamitsos, E. I.; Hausbrand, R.; Jaegermann, W. Phosphate Structure and Lithium Environments in Lithium Phosphorus Oxynitride Amorphous Thin Films. Ionics (Kiel). 2016, 22 (4), 471-481.

(20) Li, D.; Ma, Z.; Xu, J.; Li, Y.; Xie, K. High Temperature Property of All-Solid-State Thin Film Lithium Battery Using LiPON Electrolyte. Mater. Lett. 2014, 134, 237-239.

(21) Nimisha, C. S.; Rao, K. Y.; Venkatesh, G.; Rao, G. M.; Munichandraiah, N. Sputter Deposited LiPON Thin Films from Powder Target as Electrolyte for Thin Film Battery Applications. Thin Solid Films 2011, 519 (10), 3401-3406.

(22) Mascaraque, N.; Fierro, J. L. G.; Durán, A.; Muñoz, F. An Interpretation for the Increase of Ionic Conductivity by Nitrogen Incorporation in LiPON Oxynitride Glasses. Solid State Ionics 2013, 233, 73-79.

(23) Hamon, Y.; Douard, A.; Sabary, F.; Marcel, C.; Vinatier, P.; Pecquenard, B.; Levasseur, A. Influence of Sputtering Conditions on Ionic Conductivity of LiPON Thin Films. Solid State Ionics 2006, 177 (3-4), 257-261.

(24) Vieira, E. M. F.; Ribeiro, J. F.; Silva, M. M.; Barradas, N. P.; Alves, E.; Alves, A.; Correia, M. R.; Goncalves, L. M. Electrical Insulation Properties of RF-Sputtered LiPON Layers towards Electrochemical Stability of Lithium Batteries. J. Phys. D. Appl. Phys. 2016, 49 (48), 485301.

(25) Mani, P. D.; Saraf, S.; Singh, V.; Real-Robert, M.; Vijayakumar, A.; Duranceau, S. J.; Seal, S.; Coffey, K. R. Ionic Conductivity of Bias Sputtered Lithium Phosphorus Oxy-Nitride Thin Films. Solid State Ionics 2016, 287, 48-59.

(26) Jacke, S.; Song, J.; Dimesso, L.; Brötz, J.; Becker, D.; Jaegermann, W. Temperature 
Dependent Phosphorous Oxynitride Growth for All-Solid-State Batteries. J. Power Sources 2011, 196 (16), 6911-6914.

(27) Sepúlveda, A.; Speulmanns, J.; Vereecken, P. M. Bending Impact on the Performance of a Flexible Li4Ti5O12-Based All-Solid-State Thin-Film Battery. Sci. Technol. Adv. Mater. 2018.

(28) Meersschaut, J.; Vandervorst, W. High-Throughput Ion Beam Analysis at Imec. Nucl. Instruments Methods Phys. Res. Sect. B Beam Interact. with Mater. Atoms 2017, 406, 25-29.

(29) Hausbrand, R.; Schwöbel, A.; Jaegermann, W.; Motzko, M.; Ensling, D. Surface and Interface Analysis of LiCoO2 and LiPON Thin Films by Photoemission: Implications for Li-Ion Batteries. Zeitschrift für Phys. Chemie 2015, 229 (9).

(30) Chiu, K.-F.; Chen, C. C.; Lin, K. M.; Lo, C. C.; Lin, H. C.; Ho, W.-H.; Jiang, C. S. Lithium Phosphorus Oxynitride Solid-State Thin-Film Electrolyte Deposited and Modified by Bias Sputtering and Low Temperature Annealing. J. Vac. Sci. Technol. A Vacuum, Surfaces, Film. 2010, 28 (4), 568-572.

(31) Dalal, S. S.; Fakhraai, Z.; Ediger, M. D. High-Throughput Ellipsometric Characterization of Vapor-Deposited Indomethacin Glasses. J. Phys. Chem. B 2013.

(32) Swallen, S. F.; Kearns, K. L.; Mapes, M. K.; Kim, Y. S.; McMahon, R. J.; Ediger, M. D.; Wu, T.; Yu, L.; Satija, S. Organic Glasses with Exceptional Thermodynamic and Kinetic Stability. Science 2007, 315 (5810), 353-356.

(33) Leon-Gutierrez, E.; Sepúlveda, A.; Garcia, G.; Clavaguera-Mora, M. T.; Rodríguez-Viejo, J. Stability of Thin Film Glasses of Toluene and Ethylbenzene Formed by Vapor Deposition: An in Situ Nanocalorimetric Study. Phys. Chem. Chem. Phys. 2010, 12 (44), 14693-14698.

(34) Sepúlveda, a; Swallen, S. F.; Ediger, M. D. Manipulating the Properties of Stable Organic Glasses Using Kinetic Facilitation. J. Chem. Phys. 2013, 138 (12), 12 A517.

(35) Sepúlveda, a; Swallen, S. F.; Kopff, L. a; McMahon, R. J.; Ediger, M. D. Stable Glasses of Indomethacin and $\alpha, \alpha, \beta$-Tris-Naphthylbenzene Transform into Ordinary Supercooled Liquids. J. Chem. Phys. 2012, 137 (20), 204508.

(36) Whitaker, K. R.; Scifo, D. J.; Ediger, M. D.; Ahrenberg, M.; Schick, C. Highly Stable Glasses of Cis-Decalin and Cis/Trans-Decalin Mixtures. J. Phys. Chem. B 2013. 
(37) Yu, H.-B.; Luo, Y.; Samwer, K. Ultrastable Metallic Glass. Adv. Mater. 2013, 25 (41), 59045908.

(38) Guo, Y.; Morozov, A.; Schneider, D.; Chung, J. W.; Zhang, C.; Waldmann, M.; Yao, N.; Fytas, G.; Arnold, C. B.; Priestley, R. D. Ultrastable Nanostructured Polymer Glasses. Nat. Mater. 2012, 11 (4), 337-343.

(39) Beasley, M. S.; Tylinski, M.; Chua, Y. Z.; Schick, C.; Ediger, M. D. Glasses of Three Alkyl Phosphates Show a Range of Kinetic Stabilities When Prepared by Physical Vapor Deposition. J. Chem. Phys. 2018.

(40) Singh, S.; Ediger, M. D.; de Pablo, J. J. Ultrastable Glasses from in Silico Vapour Deposition. Nat. Mater. 2013, 12 (2), 139-144.

(41) Rodr?guez-Tinoco, C.; Gonzalez-Silveira, M.; R?fols-Rib?, J.; Garcia, G.; Rodr?guez-Viejo, J. Highly Stable Glasses of Celecoxib: Influence on Thermo-Kinetic Properties, Microstructure and Response towards Crystal Growth. J. Non. Cryst. Solids 2015, 407, 256-261.

(42) Aji, D. P. B.; Hirata, A.; Zhu, F.; Pan, L.; Reddy, K. M.; Song, S.; Liu, Y.; Fujita, T.; Kohara, S.; Chen, M. Ultrastrong and Ultrastable Metallic Glass. 2013.

(43) Li, G.; Li, M.; Dong, L.; Song, H.; Dong, L.; Deng, J.; Li, D. The Influence of Change in Structural Characteristics Induced by Beam Current on Mechanical Properties of LiPON Solid-State Electrolyte Films. Int. J. Hydrogen Energy 2014, 39 (28), 16103-16109.

(44) Music, D.; Kreissig, U.; Czigány, Z.; Helmersson, U.; Schneider, J. M. Elastic ModulusDensity Relationship for Amorphous Boron Suboxide Thin Films. Appl. Phys. A Mater. Sci. Process. 2003, 76 (2), 269-271.

(45) Kamitsos, E. I.; Dussauze, M.; Varsamis, C.-P. E.; Vinatier, P.; Hamon, Y. Thin Film Amorphous Electrolytes: Structure and Composition by Experimental and Simulated Infrared Spectra. J. Phys. Chem. C 2007, 111 (22), 8111-8119.

(46) Sicolo, S.; Albe, K. First-Principles Calculations on Structure and Properties of Amorphous Li5P4O8N3 (LiPON). J. Power Sources 2016, 331, 382-390.

(47) Gujral, A.; O’Hara, K. A.; Toney, M. F.; Chabinyc, M. L.; Ediger, M. D. Structural Characterization of Vapor-Deposited Glasses of an Organic Hole Transport Material with X- 
Ray Scattering. Chem. Mater. 2015, 27 (9), 3341-3348.

(48) Dalal, S. S.; Sepúlveda, A.; Pribil, G. K.; Fakhraai, Z.; Ediger, M. D. Density and Birefringence of a Highly Stable $\alpha, \alpha, \beta$-Trisnaphthylbenzene Glass. J. Chem. Phys. 2012, 136 (20), 204501.

(49) Dabas, P.; Hariharan, K. Lithium Rich Phosphate Glass: Crystallization Kinetics, Structural and Conduction Characteristics. J. Non. Cryst. Solids 2012, 358 (2), 252-260.

(50) Dabas, P.; Hariharan, K. Nucleation and Crystallization Kinetics of Rapidly Quenched Lithium Pyrophosphate Glass. Solid State Ionics 2013, 243, 42-49.

(51) Dabas, P.; Subramanian, V.; Hariharan, K. Effect of Quenching Rate on the Structure, Ion Transport, and Crystallization Kinetics in Lithium-Rich Phosphate Glass. J. Mater. Sci. 2014, $49(1), 134-141$.

(52) Sepúlveda, A.; Leon-Gutierrez, E.; Gonzalez-Silveira, M.; Clavaguera-Mora, M. T.; Rodríguez-Viejo, J. Anomalous Transformation of Vapor-Deposited Highly Stable Glasses of Toluene into Mixed Glassy States by Annealing Above T G. J. Phys. Chem. Lett. 2012, 3 (7), 919-923.

(53) Verde, M. G.; Baggetto, L.; Balke, N.; Veith, G. M.; Seo, J. K.; Wang, Z.; Meng, Y. S. Elucidating the Phase Transformation of Li 4 Ti 5 O 12 Lithiation at the Nanoscale. ACS Nano 2016, 10 (4), 4312-4321.

(54) Santhanagopalan, D.; Qian, D.; McGilvray, T.; Wang, Z.; Wang, F.; Camino, F.; Graetz, J.; Dudney, N.; Meng, Y. S. Interface Limited Lithium Transport in Solid-State Batteries. J. Phys. Chem. Lett. 2014, 5 (2), 298-303.

(55) Yu, Z.; Xu, H.; Zhu, G.; Yan, D.; Yu, A. Lithium Titanium Oxynitride Thin Film with Enhanced Lithium Storage and Rate Capability. Appl. Surf. Sci. 2016, 368, 173-176.

(56) Wang, B.; Wang, J.; Cao, J.; Ge, H.; Tang, Y. Nitrogen-Doped Li4Ti5O12 Nanosheets with Enhanced Lithium Storage Properties. J. Power Sources 2014, 266, 150-154. 